Rev. Bras. Saúde Prod. Anim., Salvador, v.13, n.3, p.619-628 jul./set., 2012 http://www.rbspa.ufba.br ISSN 15199940

\title{
Inoculação na ensilagem de parte aérea e espiga de milho, submetidas à geada
}

\author{
Inoculation in corn silages, aerial part and ear of corn, submitted to frost
}

\author{
MORAIS, Maria da Graça ${ }^{1}$; ÍTAVO, Camila Celeste Brandão Ferreira ${ }^{*}$; ÍTAVO, Luís \\ Carlos Vinhas ${ }^{2}$; BUNGENSTAB, Davi José ${ }^{3}$; COUTINHO, Marcelo Aranda da Silva ${ }^{1}$; \\ RIBEIRO, Caroline Bertholini ${ }^{1}$; OLIVEIRA, Lincoln Bremm ${ }^{1}$
}

\author{
${ }^{1}$ Universidade Federal de Mato Grosso do Sul, Faculdade de Medicina Veterinária e Zootecnia, Programa \\ de Pós-Graduação em Ciência Animal, Campo Grande, Mato Grosso do Sul, Brasil. \\ ${ }^{2}$ Universidade Católica Dom Bosco, Programa de Pós-Graduação em Ciências Ambientais e \\ Sustentabilidade Agropecuária, Campo Grande, Mato Grosso do Sul, Brasil. \\ ${ }^{3}$ Embrapa Gado de Corte, Campo Grande, Mato Grosso do Sul, Brasil. \\ *Endereço para correspondência: camila.itavo@ufms.br
}

\section{RESUMO}

Objetivou-se avaliar a fermentação e a composição química de silagens da parte aérea e da espiga de milho, submetidas ou não à geada. Avaliou-se a inoculação microbiana, no experimento 1 , da silagem de parte aérea de milho, e no experimento 2 , da silagem de espiga de milho, submetidas ou não à geada, em delineamento inteiramente casualizado, em esquema fatorial $2 \times 2$. Em silagens de parte aérea de milho, a inoculação não influenciou os teores de matéria seca (MS), matéria orgânica (MO), proteína bruta (PB) e fibra em detergente neutro (FDN) e a digestibilidade in vitro da matéria seca (DIVMS), com média de 57,49\%, e nitrogênio amoniacal (N-NH3) e perdas de MS, com médias iguais a $6,07 \% \mathrm{~N}$ total e $0,99 \%$, respectivamente. A geada acarretou menor teor de MS, 23,05\% vs 26,48\%MS, respectivamente, e maior teor de PB das silagens, 7,13 vs $6,00 \%$ PB. As silagens de espiga de milho expostas à geada apresentaram maiores teores de MS e MO, sem influência nos teores de PB, $1,71 \%$. A geada afetou a composição química das silagens da parte aérea de milho e da espiga de milho e todas apresentaram $\mathrm{pH}$ adequado. Constatou-se que a inoculação não influencia a fermentação e composição química das silagens de parte aérea de milho e de espiga de milho submetidas à geada.

Palavras-chave: aditivo microbiano, intempérie, Zea mays.

\section{SUMMARY}

Two experiments were run to evaluate the fermentation and the chemical composition of corn silages, aerial part and ear of corn, submitted or not to frost, with or without microbial inoculation, both completely randomized experimental design, in $2 \times 2$ factorial arrangement. Samples were taken before and after of ensilage. In the aerial part silage, inoculation did not influence the dry matter (DM), organic matter (OM), crude protein $(\mathrm{CP})$ and neutral detergent fiber (NDF) and in vitro digestibility of dry matter (IVDDM), with an average of $57.49 \%$, and ammonia-N $\left(\mathrm{NH}_{3}-\mathrm{N}\right)$ and $\mathrm{DM}$ losses, with means equal to $6.07 \%$ total $\mathrm{N}$ and $0.99 \%$ respectively. The frost caused lower DM content, $23.05 \%$ vs $26.48 \% \mathrm{DM}$, respectively, and higher CP content of silages, 7.13 vs $6.00 \%$ $\mathrm{CP}$. The ear of corn silage exposed to frost had higher DM and OM, without influence on $\mathrm{CP}$, $1.71 \%$. The frost affected the chemical composition of corn silages, aerial part and ear of corn, and they had proper $\mathrm{pH}$. Inoculation did not influence the fermentation and chemical composition of corn silages, aerial part and ear of corn, submitted or not to frost.

Keywords: bad weather, microbial additive, Zea mays. 


\section{INTRODUÇÃOO}

A cultura do milho safrinha, no Brasil, ocupa uma área de aproximadamente três milhões de hectares e corresponde a $25 \%$ da produção nacional desse cereal (PEREIRA \& TERRA, 2008). Em Mato Grosso do Sul, o plantio de milho safrinha tem aumentado em função da cultura da soja ocupar, na estação do verão, a maioria das áreas destinadas para produção de grãos (XIMENES et al., 2004).

Entretanto, a época da safrinha é caracterizada por baixas temperaturas, com maior incidência de geadas, que provocam alterações no metabolismo vegetal. Nas plantas, os cristais de gelo formam-se primeiro nas partes que se resfriam e que são mais propensas ao congelamento, geralmente os feixes vasculares periféricos (XIMENES et al., 2004). Protoplasto com alta proporção de água sofre congelamento intracelular de maneira repentina, o que causa a destruição do citoplasma (LARCHER, 2000). Após o congelamento, promovido pela geada, ocorre o extravasamento das células rompidas, percebido pela mudança da coloração das folhas, que passam de verde escuro, no primeiro dia após a geada, para coloração marrom, até chegar à cor palha (PEREIRA \& TERRA, 2008).

A depender da intensidade da geada pode ocorrer perda total da lavoura, de modo a restar ao produtor à opção de corte e ensilagem. No processo de ensilagem, a preservação do alimento é realizada pela fermentação bacteriana de açúcares em ambiente anaeróbico, com o abaixamento do $\mathrm{pH}$ devido à produção dos ácidos lático e acético (McDonald, 1981)

A qualidade da silagem de milho varia de acordo com o processo de ensilagem, condições climáticas, microbiota epifítica, teor de matéria seca, carboidratos solúveis e substâncias nitrogenadas. Inoculantes compostos principalmente por bactérias ácidolácticas têm sido usados como aditivos em silagens para melhoria da eficiência de preservação e, em alguns casos, tem sido observado o efeito da inoculação da silagem sobre o desempenho dos animais (WEINBERG et al., 2007).

Em relação ao uso de aditivos microbianos, Ítavo et al. (2006) verificaram que não houve melhoria no padrão de fermentação em silagens de grãos úmidos de milho. Já Rocha et al. (2006) encontraram efeito positivo sobre o valor nutritivo de silagens de milho (Zea mays L.) produzidas com inoculantes enzimo-bacterianos.

Nesse contexto, objetivou-se avaliar as silagens de parte aérea e de espiga de milho, submetidas ou não à geada, com uso ou não de inoculante microbiano.

\section{MATERIAL E MÉTODOS}

Os experimentos foram conduzidos nas dependências da Universidade Federal de Mato Grosso do Sul, em Campo Grande-MS. A colheita e ensilagem do milho foram realizadas na Fazenda Triângulo, localizada no município de Maracaju- MS.

No experimento 1, foi realizada a inoculação na ensilagem de parte aérea de milho, submetida ou não à geada, onde os tratamentos foram estabelecidos de acordo com as condições climáticas sofridas pela plantação (com ou sem geada) e processo de ensilagem (com ou sem adição de inoculante). O cultivar de milho utilizado foi A4454 e utilizou-se como critério a linha de leite, com colheita aleatória das plantas em diferentes áreas (com ou sem incidência de geada), após sete dias da ocorrência 
da geada. A parte aérea do milho foi processada em triturador, com 5$10 \mathrm{~mm}$, com posterior adição ou não do inoculante bacteriano de forma homogênea nos respectivos tratamentos: parte aérea do milho, submetida à geada, com inoculante, parte aérea do milho, submetida à geada, sem inoculante, parte aérea do milho, não submetida à geada, com inoculante, e parte aérea do milho, não submetida à geada, sem inoculante.

No experimento 2, foi realizada a inoculação na ensilagem de espigas de milho, submetidas ou não à geada, sendo os tratamentos estabelecidos de acordo com as condições climáticas sofridas pela plantação (com ou sem geada) e processo de ensilagem (com ou sem adição de inoculante). O cultivar de milho utilizado foi A4454 e utilizou-se como critério a linha de leite, com colheita aleatória das espigas em diferentes áreas (com ou sem incidência de geada), após sete dias da ocorrência da geada. A espiga do milho foi colhida e processada em triturador, em 5$10 \mathrm{~mm}$, com posterior adição ou não do inoculante bacteriano, de forma homogênea nos respectivos tratamentos: espiga do milho, submetida à geada, com inoculante, espiga do milho, submetida à geada, sem inoculante, espiga do milho, não submetida à geada, com inoculante, $\mathrm{e}$ espiga do milho, não submetida à geada, sem inoculante.

Em ambos os ensaios, o inoculante utilizado foi o Maize-All® da Alltech, composto de: Streptococcus (Enterococcus) faecium (10bilhões UFC/g), Lactobacillus plantarum (10 bilhões UFC/g) e Pediococcus acidilactici (1bilhão UFC/g), enzimas amilolíticas (2\%), enzimas celulolíticas $(1,5 \%)$ e dextrose, adicionado após o processamento, de forma homogênea, por aspersão, de acordo com as recomendações do fabricante.
O material processado foi ensilado, em silos experimentais de PVC $(50 \mathrm{~cm}$ de comprimento e $100 \mathrm{~mm}$ de diâmetro), com capacidade de aproximadamente $3,0 \mathrm{~kg}$. Os silos eram providos de válvulas do tipo "Bunsen", de forma a impedir a entrada de ar e permitir o livre escape dos gases da fermentação. Foram utilizados 8 silos laboratoriais por tratamento, com ou sem inoculante, o que totalizou 32 silos por experimento. A densidade de ensilagem para as silagens de parte aérea de milho e de espiga de milho foi igual a 709,74 e $842,72 \mathrm{~kg} / \mathrm{m}^{3}$, respectivamente. Os microssilos foram mantidos à sombra, em temperatura ambiente. Amostras foram tomadas antes (Tabelas 1 e 2) e aos 41 dias após a ensilagem. Os silos foram pesados ao enchimento e antes da abertura, para estimação das perdas de MS, durante o processo fermentativo.

Após a abertura dos silos, procedeu-se à determinação do $\mathrm{pH}$, em água, de cada silagem (SILVA \& QUEIROZ, 2002). Posteriormente, amostras foram retiradas, devidamente identificadas e congeladas para posteriores análises. Para a realização das análises químicas, as amostras foram descongeladas, pré-secas em estufa de ventilação forçada, à $55^{\circ} \mathrm{C}$, por 72 horas e trituradas em moinho do tipo "Willey" em crivos de $1 \mathrm{~mm}$. Determinaram-se os teores de matéria seca (MS), nitrogênio total para obtenção da proteína bruta (PB) e cinzas para obtenção da matéria orgânica (MO) e fibra em detergente neutro (FDN) (Silva \& Queiroz, 2002). O teor de nitrogênio amoniacal $\left(\mathrm{N}-\mathrm{NH}_{3}\right)$ foi mensurado por meio de metodologia descrita por Playne \& McDonald (1966). Análises de digestibilidade in vitro da matéria seca (DIVMS) das silagens de parte aérea de milho foram realizadas segundo Tilley \& Terry (1963), com uso de líquido ruminal de bovinos machos castrados com fístulas 
Rev. Bras. Saúde Prod. Anim., Salvador, v.13, n.3, p.619-628 jul./set., 2012 http://www.rbspa.ufba.br ISSN 15199940

ruminais, que recebiam dietas com concentrado, para adaptação da microbiota ruminal aos altos teores de carboidratos presentes nas silagens. Utilizou-se o seguinte modelo estatístico: $\mathrm{Y}_{\mathrm{ijk}}=\mu+\mathrm{A}_{\mathrm{i}}+\mathrm{I}_{\mathrm{j}}+\mathrm{AI}_{\mathrm{ij}}+\mathrm{e}_{\mathrm{ijk}}$, no qual, $\mathrm{Y}_{\mathrm{ijk}}$ é a observação $\mathrm{j}$, referente ao tratamento com aditivo $\mathrm{i}$ e intempérie $\mathrm{j}$; $\mu$ é a constante geral; $A_{i}$ é o efeito com tratamento do aditivo $\mathrm{i}, \mathrm{i}=1$ e $2 ; \mathrm{I}_{\mathrm{j}}$ é o efeito com tratamento da intempérie $\mathrm{j}, \mathrm{j}=$
1 e $2, \mathrm{AP}_{\mathrm{ij}}$ é a interação entre aditivo e intempérie e $\varepsilon_{\mathrm{ijk}}$ é o erro aleatório associado a cada observação $\mathrm{Y}_{\mathrm{ijk}}$. Os tratamentos foram arranjados em delineamento inteiramente casualizado, em esquema fatorial 2 × 2 (geada ou não, adição ou não de inoculante), com oito repetições, o que totalizou 32 amostras. Os dados foram avaliados por meio de análises variância e as médias comparadas pelo teste Tukey.

Tabela 1. Teores de matéria seca (MS), matéria orgânica (MO), proteína bruta (PB), fibra em detergente neutro (FDN) e valores de $\mathrm{pH}$ de parte aérea da planta de milho, em função da intempérie (geada ou não) e do uso ou não de inoculante antes da ensilagem

\begin{tabular}{lrcrc}
\hline \multirow{2}{*}{ Item } & \multicolumn{2}{c}{ Normal } & \multicolumn{2}{c}{ Geada } \\
\cline { 2 - 5 } & Controle & Inoculada & Controle & Inoculada \\
\hline MS (\%) & 26,51 & 26,38 & 25,31 & 24,79 \\
MO (\% MS) & 96,33 & 96,31 & 95,20 & 95,01 \\
PB (\% MS) & 5,85 & 6,10 & 7,06 & 6,67 \\
FDN (\% MS) & 61,33 & 59,95 & 62,16 & 59,88 \\
pH & 4,70 & 4,80 & 4,80 & 4,56 \\
\hline
\end{tabular}

Tabela 2. Teores de matéria seca (MS), matéria orgânica (MO), proteína bruta $(\mathrm{PB})$, fibra em detergente neutro (FDN), nitrogênio amoniacal $\left(\mathrm{N}_{-} \mathrm{NH}_{3}\right)$ e valores de pH de espiga de milho, em função da intempérie (geada ou não) e do uso ou não de inoculante antes da ensilagem

\begin{tabular}{lrcrc}
\hline \multirow{2}{*}{ Item } & \multicolumn{2}{c}{ Normal } & \multicolumn{2}{c}{ Geada } \\
\cline { 2 - 5 } & Controle & Inoculada & Controle & Inoculada \\
\hline MS (\%) & 41,04 & 40,41 & 43,67 & 43,74 \\
MO (\% MS) & 97,87 & 98,01 & 98,26 & 98,24 \\
PB (\% MS) & 1,64 & 1,79 & 1,68 & 1,71 \\
FDN (\% MS) & 43,43 & 39,99 & 38,63 & 39,85 \\
pH & 5,82 & 5,10 & 5,68 & 5,70 \\
\hline
\end{tabular}

\section{RESULTADOS E DISCUSSÃO}

No experimento 1, foi realizada a inoculação na ensilagem de parte aérea de milho, submetida ou não à geada. $\mathrm{O}$ uso do aditivo enzimático bacteriano não teve efeito significativo sobre o teor de MS, após 41 dias de ensilagem (Tabela 3) da parte aérea do milho. Os teores de MS, MO, PB e FDN e os valores de DIVMS de silagens de parte aérea de milho não foram influenciados pela inoculação. Entretanto, a ocorrência de geada acarretou menores teores de MS e $\mathrm{MO}$ e maior teor de PB das silagens. 
Tabela 3. Teores de matéria seca (MS), matéria orgânica (MO), proteína bruta (PB), nitrogênio total (N-total), nitrogênio amoniacal $\left(\mathrm{N}-\mathrm{NH}_{3}\right), \mathrm{pH}$, digestibilidade in vitro da MS (DIVMS) e perdas de MS de silagens de parte aérea da planta de milho em função da intempérie (geada ou não) e do uso ou não de inoculante

\begin{tabular}{|c|c|c|c|c|c|c|c|c|}
\hline \multirow{2}{*}{ Item } & \multicolumn{2}{|c|}{ Normal } & \multicolumn{2}{|c|}{ Geada } & \multirow{2}{*}{$\begin{array}{l}\mathrm{CV} \\
(\%)\end{array}$} & \multirow{2}{*}{$\begin{array}{c}\text { Valor de P } \\
\text { (Intempérie) }\end{array}$} & \multirow{2}{*}{$\begin{array}{l}\text { Valor de P } \\
\text { (Inoculante) }\end{array}$} & \multirow{2}{*}{$\begin{array}{l}\text { Valor de P } \\
\text { (Interação) }\end{array}$} \\
\hline & Controle & Inoculada & Controle & Inoculada & & & & \\
\hline \multicolumn{9}{|c|}{ Composição bromatológica e digestibilidade in vitro das silagens } \\
\hline MS (\%) & $26,55^{\mathrm{a}}$ & $26,40^{\mathrm{a}}$ & $23,07^{\mathrm{b}}$ & $23,03^{b}$ & 3,24 & 0,00001 & NS & NS \\
\hline $\mathrm{MO}(\% \mathrm{MS})$ & $95,63^{\mathrm{a}}$ & $95,81^{\text {a }}$ & $94,82^{\mathrm{b}}$ & $94,96^{\mathrm{b}}$ & 8,76 & 0,00001 & NS & NS \\
\hline $\mathrm{PB}(\% \mathrm{MS})$ & $5,86^{\mathrm{b}}$ & $6,14^{\mathrm{b}}$ & $7,09^{\mathrm{a}}$ & $7,16^{\mathrm{a}}$ & 4,91 & 0,00001 & 0,13032 & NS \\
\hline FDN (\% MS) & 55,66 & 59,83 & 53,38 & 61,17 & 27,28 & NS & 0,29018 & NS \\
\hline DIVMS (\% MS) & 57,17 & 56.86 & 57,34 & 58,58 & 3,70 & 0,21961 & NS & 0,31332 \\
\hline \multicolumn{9}{|c|}{ Parâmetros de fermentação das silagens } \\
\hline Perdas (\% MS) & 0,74 & 1,27 & 0,55 & 1,40 & 112,24 & NS & 0,08985 & NS \\
\hline $\mathrm{pH}$ & 3,84 & 3,71 & 3,57 & 3,64 & 0,75 & 0,00001 & 0,01063 & 0,00001 \\
\hline $\mathrm{N}-\mathrm{NH}_{3}(\% \mathrm{~N}$ total $)$ & 6,47 & 5,83 & 5,97 & 6,02 & 19,42 & NS & NS & $\mathrm{NS}$ \\
\hline
\end{tabular}

Médias na mesma linha seguidas por letras minúsculas diferentes diferem entre si pelo teste Tukey a $5 \%$ de significância $(\mathrm{P}<0,05)$. 
O maior teor de $\mathrm{PB}$, possivelmente, está relacionado a um processo de concentração de nutrientes, devido aos menores teores de MS e MO causados pela geada, o que concorda com os relatos de Ximenes et al. (2004), que afirmaram que, nas plantas, os cristais de gelo formam-se primeiro nas partes que se resfriam e que são mais propensas ao congelamento, e, de maneira repentina, no interior da célula, o que causa a destruição do citoplasma (XIMENES et al., 2004). Após o derretimento dos cristais de gelo, a perda de conteúdo celular possivelmente tenha promovido a diminuição dos teores de MS e MO, com perda de compostos mais solúveis e concentração de compostos menos solúveis, como por exemplo a $\mathrm{PB}$.

Não houve diferença $(\mathrm{P}>0,05)$ nos teores de $\mathrm{PB}$, em função do uso do inoculante, porém, maiores valores $(\mathrm{P}<0,05)$ de $\mathrm{PB}$ para a silagem, que sofreu ação da geada, foi observado, com média de 7,13 vs $6,00 \% \mathrm{~PB}$, possivelmente, pela concentração de nutrientes, após o extravasamento de conteúdo celular. Os teores de FDN de silagens da parte aérea de milho não foram influenciados $(\mathrm{P}>0,05)$ pela ação da geada e pela inoculação, cujo valor médio foi de $57,51 \%$, inferior aos $62,39 \%$ obtidos por Rodrigues et al. (2004).

Não se observou influência $(P>0,05)$ da ação da geada sobre a DIVMS da silagem, com média de 57,49\%, semelhante aos valores apresentados por Santos et al. (2010), ao avaliarem as características de fermentação da silagem de seis variedades de milho, indicadas para região semi-árida brasileira.

A DIVMS não foi afetada $(\mathrm{P}>0,05)$ pelo inoculante, $\mathrm{e}$ foram observados os valores 56,86 e 58,58\% para silagens de parte aérea do milho submetidas ou não a geada, que são superiores aos encontrados por Rodrigues et al. (2004) de 47,08 e 46,76\%, com inoculante e sem inoculante, respectivamente. Foi encontrada diferença significativa $(\mathrm{P}<0,05)$ para os valores de $\mathrm{pH}$ na silagem, com valores menores para os tratamentos que sofreram ação da geada. Rodrigues et al. (2004), ao avaliarem a silagem de milho com ou sem a adição de inoculante bacteriano, encontraram valores maiores de $\mathrm{pH}$, 4,03 e 4,05, para tratamentos com a adição ou não de inoculantes, respectivamente. Entretanto, os valores obtidos estão dentro da faixa recomendada por McDonald (1981), 3,8 a 4,2 , como indicativo de boa conservação da massa ensilada.

Os teores de $\mathrm{N}_{-} \mathrm{NH}_{3}$ não foram influenciados pela geada e inoculação, com média igual a $6,07 \% \mathrm{~N}$ total, e apresentaram-se parcialmente superiores aos $4,43 \% \mathrm{~N}-\mathrm{NH}_{3}$, em relação ao $\mathrm{N}$ total apresentados por Rocha et al. (2006), que avaliaram o valor nutritivo de silagens de milho (Zea mays L.), produzidas com mesmo inoculante enzimo-bacteriano utilizado neste ensaio. Entretanto, os teores de nitrogênio amoniacal obtidos, neste experimento, foram inferiores aos $7,7 \% \mathrm{~N}$ total em silagens de milho, apresentados por Oliveira et al. (2010).

Não houve diferença quanto às perdas de MS das silagens de parte aérea de milho, com relação à geada ou inoculação, com média igual a $0,99 \%$. Tal valor obtido está relacionado às perdas intrínsecas ao processo de ensilagem e demonstra que o processo foi realizado de maneira adequada, no qual se pode destacar a densidade de $709,74 \mathrm{~kg} / \mathrm{m}^{3}$ do material ensilado.

Segundo Zopollatto et al. (2009), a obtenção de sucesso no uso de aditivos microbiológicos, em silagens, depende da habilidade que a bactéria inoculada tem em crescer rapidamente na massa de forragem ensilada, da presença de substrato adequado e da população de bactérias inoculadas em relação à 
população epífita da forragem. Nesse sentido, possivelmente, a geada não influenciou a população microbiana epífitica das plantas de milho, de modo a promover adequado padrão de fermentação das silagens, mas sim a quantidade de substrato disponível para fermentação na parte aérea da planta de milho.

No experimento 2, foi realizada a inoculação de silagens de espigas de milho, submetidos ou não a geada, houve diferença nos teores de MS e MO das silagens de espiga de milho, em função da intempérie. Cabe destacar que as silagens de espiga de milho expostas à geada apresentaram os maiores teores de MS e MO (Tabela 4). Possivelmente, o maior teor de MS e MO obtido em silagens de espigas de milho, submetidas à geada, esteja relacionado ao fato de que, apesar da geada ter afetado a plantação como um todo, a queima das folhas propicia, naturalmente, a translocação de fotoassimilados para a espiga, com objetivo de continuar o processo de enchimento dos grãos Carter \& Hesterman (2001). Ximenes et al. (2004) também relataram que o acúmulo de matéria seca na espiga é inversamente proporcional aos danos causados a área foliar das plantas.

Não houve diferença significativa para os teores de PB entre silagens de espiga de milho, em função da intempérie e da inoculação. Rocha et al. (2006) observaram efeito $(\mathrm{P}<0,05)$ do inoculante Maize All ${ }^{\circledR}$ sobre os teores de PB de silagens inoculadas e controle, com valores médios de 6,7 e $6,3 \%$, respectivamente, o que foi atribuído a menor proteólise nas silagens tratadas com inoculantes, de modo a resultar, portanto, em melhor conservação do teor proteico dessas silagens. Isso não ocorreu nas silagens de espigas de milho, o que pode ser atribuído a diversos fatores como a população epifítica do material ensilado, mas fundamentalmente, ao menor teor proteico característico do material espiga de milho, com média de $1,71 \%$ de PB.

Já em relação aos teores de FDN, não houve diferença significativa, mesmo com a presença de enzimas amilolíticas (2\%) e enzimas celulolíticas (1,5\%) no aditivo utilizado, porém Rodrigues et al. (2004), ao trabalharem com diferentes inoculantes, sugeriram que a presença de enzimas celulolíticas e hemicelulolíticas no inoculante pode ocasionar redução no teor de FDN da silagem.

Os valores de $\mathrm{pH}$ não foram influenciados pela inoculação microbiana. Houve influência da geada nos valores de $\mathrm{pH}$, e as silagens de espiga de milho, submetidas à geada, apresentaram maior valor de $\mathrm{pH}$. Contudo, o valor apresentado nos diferentes tratamentos indica que o processo de fermentação foi realizado adequadamente, devido aos valores permanecerem dentro da faixa recomendada, entre 3,8 e 4,2 , por McDonald (1981).

Com relação ao $\mathrm{N}-\mathrm{NH}_{3}$, a inoculação influenciou os teores obtidos nas silagens, com menores médias para silagens de espiga de milho inoculadas, 24,76 vs $29,18 \%$ do $\mathrm{N}$ total, em comparação as silagens de espiga de milho controle. Tais valores são altos, o que indica que grande parte do pequeno teor de proteína das silagens de espiga de milho está na forma amoniacal.

Houve diferença entre os tratamentos para perdas de MS, durante o processo de ensilagem. Parte das perdas totais de MS ocorre, inevitavelmente, durante a ensilagem, no processo de respiração celular (McDONALD, 1981). Outra parte das perdas de MS são chamadas de perdas evitáveis e estão relacionadas ao manejo durante o processo de ensilagem, como por exemplo grau de compactação, tempo utilizado para enchimento e vedação, entre outros. 
Tabela 4. Teores de matéria seca (MS), matéria orgânica (MO), proteína bruta (PB), nitrogênio total (N-total), nitrogênio amoniacal $\left(\mathrm{N}-\mathrm{NH}_{3}\right), \mathrm{pH}$, digestibilidade in vitro da MS (DIVMS) e perdas de MS de silagens de espiga de milho em função da intempérie (geada ou não) e do uso ou não de inoculante

\begin{tabular}{|c|c|c|c|c|c|c|c|c|}
\hline \multirow{2}{*}{ Item } & \multicolumn{2}{|c|}{ Normal } & \multicolumn{2}{|c|}{ Geada } & \multirow{2}{*}{$\begin{array}{l}\mathrm{CV} \\
(\%)\end{array}$} & \multirow{2}{*}{$\begin{array}{c}\text { Valor de P } \\
\text { (Intempérie) }\end{array}$} & \multirow{2}{*}{$\begin{array}{c}\text { Valor de P } \\
\text { (Aditivo) }\end{array}$} & \multirow{2}{*}{$\begin{array}{l}\text { Valor de P } \\
\text { (Interação) }\end{array}$} \\
\hline & Controle & Inoculada & Controle & Inoculada & & & & \\
\hline \multicolumn{9}{|c|}{ Composição bromatológica e digestibilidade in vitro das silagens } \\
\hline MS (\%) & $43,42^{\mathrm{c}}$ & $41,04^{\mathrm{c}}$ & $44,04^{\mathrm{ab}}$ & $45,06^{\mathrm{a}}$ & 4,51 & 0,00232 & NS & 0,02065 \\
\hline MO (\% MS) & $97,94^{\mathrm{b}}$ & $97,91^{\mathrm{b}}$ & $98,27^{\mathrm{a}}$ & $98,34^{\mathrm{a}}$ & 6,86 & 0,00001 & NS & 0,27473 \\
\hline $\mathrm{PB}(\% \mathrm{MS})$ & $1,71^{\mathrm{a}}$ & 1,72 & 1,70 & 1,72 & 2,32 & NS & 0,25704 & NS \\
\hline FDN (\% MS) & 40,03 & 40,94 & 40,36 & 36,48 & 10,50 & 0,16940 & 0,32033 & 0,11355 \\
\hline \multicolumn{9}{|c|}{ Parâmetros de fermentação das silagens } \\
\hline Perdas (\% MS) & $5,11^{\mathrm{a}}$ & $5,20^{\mathrm{a}}$ & $3,94^{b}$ & $3,85^{\mathrm{b}}$ & 12,61 & 0,00001 & NS & NS \\
\hline $\mathrm{pH}$ & $3,65^{\mathrm{b}}$ & $3,62^{\mathrm{b}}$ & $3,70^{\mathrm{a}}$ & $3,72^{\mathrm{a}}$ & 2,57 & 0,02942 & NS & NS \\
\hline $\mathrm{N}-\mathrm{NH}_{3}(\% \mathrm{~N}$ total $)$ & $27,99^{\mathrm{b}}$ & $23,79^{\mathrm{a}}$ & $30,36^{\mathrm{b}}$ & $25,72^{\mathrm{a}}$ & 20,15 & 0,27356 & 0,02906 & NS \\
\hline
\end{tabular}

Médias na mesma linha seguidas por letras minúsculas diferentes diferem entre si pelo teste Tukey a 5\% de significância $(\mathrm{P}<0,05)$. 
Neste experimento, não houve influência da inoculação sobre as perdas de MS, entretanto, a geada proporcionou menores perdas de MS da silagem de espiga de milho, o que possivelmente está relacionado à translocação de fotoassimilados para a espiga, com objetivo de continuar o processo de enchimento dos grãos (CARTER \& HESTERMAN, 2001), com aumento do teor de MS e menor ocorrência de perdas de MS.

De maneira geral, as perdas de MS foram consideráveis, o que, possivelmente, está relacionado à maior presença de sabugo no processo de ensilagem, o que dificulta a compactação, no sentido de permitir a presença de moléculas de oxigênio entre a massa ensilada. Nesse sentido, Jobim et al. (1997) avaliaram a presença de microrganismos na silagem de grãos úmidos de milho ensilado com diferentes proporções de sabugo e verificaram que a presença de enterobactérias e leveduras foi maior em função da maior inclusão de sabugo nas silagens, o que pode ser preocupante em relação à estabilidade aeróbia do material ensilado. Também, Ítavo et al. (2010) verificaram que a inoculação não se faz necessária na confecção de silagens de cana-de-açúcar e capim-elefante.

Tais resultados obtidos corroboram com os achados de Zopollato et al. (2009), que afirmaram que, de forma geral, a frequência de respostas favoráveis em valor nutritivo e padrão de fermentação resultantes de observações mais consolidadas encontradas nesse trabalho, variou entre média e baixa.

A incidência de geada na cultura de milho afeta a composição química, das silagens da parte aérea de milho e da espiga de milho, além de acarretar perdas de MS, das silagens de espigas de milho. A inoculação de silagens da parte aérea do milho e da espiga de milho, submetidas à geada, não se faz necessária, uma vez que não houve alteração no padrão de fermentação e na composição química das silagens.

\section{REFERÊNCIAS}

CARTER, P.P.; HESTERMAN, O.B. Handling corn damaged by autumm frost. Michigan State University Extension, 2011. 6p. (Field Crop CAT Alerts 1996-2001).

ÍTAVO, C.C.B.F.; MORAIS, M.G.; ÍTAVO, L.C.V., SOUZA, A.R.D.L.; DAVY, F.C.A.; ALBERTINI, T.Z.; COSTA, C.; LEMPP, B.; JOBIM, C.C. Padrão de fermentação e composição química de silagens de grãos úmidos de milho e sorgo submetidas ou não a inoculação microbiana. Revista Brasileira de Zootecnia, v.35, n.3, p.655-664, 2006.

ÍTAVO, L.C.V.; ÍTAVO, C.C.B.F.; MORAIS, M.G.;COELHO, E.M.; DIAS, A.M. Composição química e parâmetros fermentativos de silagens de capim-elefante e cana-de-açúcar tratadas com aditivos. Revista Brasileira de Saúde e Produção Animal [Online], v.11, p.606-617, 2010.

JOBIM, C.C.; REIS, R.A.; RODRIGUES, L.R.A.; SCHOCKENITURRINO, R.B. Presença de microrganismos na silagem de grãos úmidos de milho ensilado com diferentes proporções de sabugo.

Pesquisa Agropecuária Brasileira, v.32, n.2, p.201-204, 1997.

LARCHER, W. A planta sobre estresse. In: LARCHER, W. Ecofisiologia vegetal. São Paulo: Rima Artes e Textos, 2000. p.341-437. 
Rev. Bras. Saúde Prod. Anim., Salvador, v.13, n.3, p.619-628 jul./set., 2012 http://www.rbspa.ufba.br ISSN 15199940

McDONALD, P. The biochemistry of silage. New York: John Wiley, 1981. $207 \mathrm{p}$.

OLIVEIRA, L.B.; PIRES, A.J.V.; CARVALHO, G.G.P.; RIBEIRO, L.B.O.; ALMEIDA, V.V.; PEIXOTO, C.A.M. Perdas e valor nutritivo de silagens de milho, sorgo-sudão, sorgo forrageiro e girassol. Revista Brasileira de Zootecnia, v.39, n.1, p.61-67, 2010.

PEREIRA, J.R.A.; TERRA, B.

Ensilagem de lavoura de milho que sofreu geada. Santa Cruz do Sul, RS: Pionner, 2008. 4p. (Comunicado Técnico, 6).

PLAYNE, M.J., McDONALD, P. The buffering constituints of herbage and silage. Journal of Science Food and Agriculture, v.17, p.262-268, 1966.

ROCHA, K.D.; PEREIRA, O.G.; VALADARES FILHO, S.C.; OLIVEIRA, A.P.; PACHECO, L.B.B.; CHIZZOTTI, F.H.M. Valor nutritivo de silagens de milho (Zea mays L.) produzidas com inoculantes enzimobacterianos. Revista Brasileira de Zootecnia, v.35, n.2, p.389-395, 2006.

RODRIGUES, P.H.M.; RUZANTE, J.M.; SENATORE, A.L.; LIMA, F.R.; MELOTTI, L.; MEYER, P.M. Avaliação do uso de inoculantes microbianos sobre a qualidade fermentativa e nutricional da silagem de milho. Revista Brasileira de

Zootecnia, v.33, n.3, p.538-545, 2004.

SANTOS, R.D.; PEREIRA, L.G.R.; NEVES, A.L.A.; ARAÚJO, G.G.L.; VOLTOLINI, T.V.; BRANDÃO, L.G.N.; ARAGÃO, A.S.L.; DÓREA, J.R.R. Características de fermentação de silagem de seis variedades de milho indicadas para a região semiárida brasileira. Arquivo Brasileiro de
Medicina Veterinária e Zootecnia, v.62, n.6, p.1423-1429, 2010.

SILVA, D.J.; QUEIROZ, A.C. Análise de alimentos: métodos químicos e biológicos. 3.ed. Viçosa:Universidade Federal de Viçosa, 2002. 235p.

TILLEY, J.M.A., TERRY, R.A. A two stage technique for the in vitro digestion of forage crops. Journal British of Grassland Society, v.18, n.2, p.104111, 1963.

WEINBERG, Z.G.; SHATZ, O.; CHEN, Y.; YOSEF, E.; NIKBAHAT, M.; BEN-GHEDALIA, D.; MIRON, J. Effect of lactic acid bacteria inoculants on in vitro digestibility of wheat and corn silages. Journal of Dairy Science, v.90, n.10, p.4754-4762, 2007.

XIMENES, A.C.A.; SOUZA, L.C.F.; ROBAINA, A.D.; GONÇALVES, M.C. Avaliação da incidência de geadas em componentes de produtividade do milho. Revista Brasileira de Milho e Sorgo, v.3, n.2, p.214-227, 2004.

ZOPOLLATTO, M.; DANIEL, J.L.P.; NUSSIO, L.G. Aditivos microbiológicos em silagens no Brasil: revisão dos aspectos da ensilagem e do desempenho de animais. Revista Brasileira de Zootecnia, v.38, p.170189, 2009. Supl. especial.

Data de recebimento: 26/09/2011

Data de aprovação: 01/08/2012 